\title{
CERTAIN CLASSES OF ANALYTIC FUNCTIONS OF COMPLEX ORDER INVOLVING A FAMILY OF GENERALIZED DIFFERENTIAL OPERATORS
}

\author{
C. Selvaraj And K. R. Karthikeyan
}

Abstract. A new class of analytic functions of complex order is defined using a generalized differential operator. Coefficient inequalities, sufficient condition and an interesting subordination result are obtained.

Mathematics subject classification (2000): 30C45, 30C50.

Keywords and phrases: Analytic functions, Hadamard product, generalized hypergeometric functions, coefficient inequalities, subordinating sequence.

\section{REFERENCES}

[1] F. M. AL-OBoudI, On univalent functions defined by a generalized Sălăgean operator, Int. J. Math. Math. Sci. 2004, no. 25-28, 1429-1436.

[2] M. K. Aouf, S. Owa AND M. OBRadović, Certain classes of analytic functions of complex order and type beta, Rend. Mat. Appl. (7) 11 (1991), no. 4, 691-714.

[3] M. K. AOUf, H. E. DARWISH AND A. A. ATTIYA, On a class of certain analytic functions of complex order, Indian J. Pure Appl. Math. 32 (2001), no. 10, 1443-1452.

[4] A. A. ATTIYA, On a generalization class of bounded starlike functions of complex order, Appl. Math. Comput. 187 (2007), no. 1, 62-67.

[5] J. DZIOK AND H. M. SRIVASTAVA, Classes of analytic functions associated with the generalized hypergeometric function, Appl. Math. Comput. 103 (1999), no. 1, 1-13.

[6] P. L. DuREN, Univalent functions, Springer-verlag, Berlin, 1983.

[7] G. Murugusundaramoorthy and N. Magesh, Starlike and convex functions of complex order involving the Dziok-Srivastava operator, Integral Transforms Spec. Funct. 18 (2007), no. 5-6, 419-425.

[8] M. A. NASR AND M. K. AOUf, Starlike function of complex order, J. Natur. Sci. Math. 25 (1985), no. 1, $1-12$.

[9] G. Ş. SăLĂGEAN, Subclasses of univalent functions, in Complex analysis-fifth Romanian-Finnish seminar, Part 1 (Bucharest, 1981), 362-372, Lecture Notes in Math., 1013, Springer, Berlin.

[10] N. S. SOHI AND L. P. SingH, A class of bounded starlike functions of complex order, Indian J. Math. 33 (1991), no. 1, 29-35.

[11] C. Selvaraj and K. R. KarthiKeyan, Differential Subordination and Superordination For Certain Subclasses of Analytic Functions, Far East J. Math. Sci. 29 (2008), no. 2, 419-430.

[12] H. S. WILF, Subordinating factor sequences for convex maps of the unit circle, Proc. Amer. Math. Soc. 12 (1961), 689-693. 